\title{
Microstructure evolution of low alloy wear resistant steels during heat treatment procedure
}

\author{
Tianming $\mathrm{Li}^{1}$, Wenfeng Zhang ${ }^{1,2 *}$, Zhong Liu ${ }^{1}$, Xiaogang Liu ${ }^{2}$, Wei Xiong ${ }^{1}$ \\ ${ }^{1}$ School of Mechanical Engineering, Gulin University of Aerospace Technology, Guilin 541004 China \\ ${ }^{2}$ Guangxi Colleges and Universities Key Laboratory of Robot \& Welding, Guilin University of Aerospace Technology, Guilin 541004, \\ China
}

\begin{abstract}
Microstructure evolution of low alloy wear resistant steels during heat treatment procedure was studied in this paper. The results showed that During furnace cooling in homogenizing, Chromium/iron, Niobium, Vanadium and other hardly soluble carbides formed. But Chromium/iron carbides could resolve into austenite during quenching procedure, while the other carbides barely changed. Carbon addition grew the carbides into shuttle shapes and inflated the austenite grains. But Ni addition broadened the martensite lath width without dilating the austenite grains. And it hardly influenced the carbides formation. Vanadium addition seemed that the martensite lathes were cut into several discontinues sections. With the temperature rising, the boundaries got blurred, which might correlated with the decomposing of retained austenite.
\end{abstract}

\section{Introduction}

Recently, wear resistance of steel have become increasingly prominent in engineering. The loss of steel materials could be better controlled by modifying the material preparation procedure, such as smelting process, heat treatment process, rolling process, and coating. The alloy element content and heat treatment process, including temperature, isothermal holding time and cooling rate, played a significant role in improving the mechanical properties in wear resistance steels. Therefore, research in this area has attracted the attention of many researchers.

Carbon had a critical effects on the microstructure and properties of low alloy wear resistant steels ${ }^{[1]}$. Carbon would accelerate austenite forming 30 times as large as Nickel ${ }^{[2-4]}$. When Carbon content was higher than $1 \%$, acicular plate martensite became the dominant morphology. Lath structure was refined with increasing Carbon content. When Carbon content is lower than 0.27 $\mathrm{wt} \%$, lath martensite and retained austenite or lath martensite, bainite and retained martensite can be acquired when quenched into water, resulting in nice plasticity and toughness ${ }^{[5]}$. Nickel was an element that stablized austenite. Nickel, in mutual solution with iron, existed in both $\alpha$ and $\gamma$ phase of steels, and strengthened them.

Vanadium participated as carbides and nitrides in steels. Vanadium increased solving time of carbides in austenite and homogenizing time of austenite composites. Solubility of vanadium in austenite is small and it formed dispersion particles to prevent the growth of austenite ${ }^{[7]}$. Thus, it refines grains and improves steel toughness.
This work focued on effects of $\mathrm{C}, \mathrm{Ni}$ and $\mathrm{V}$ on microstructure and properties of low alloy wear resistant steels. The hardness and impact toughness of low alloy wear resistance steels with different alloy composition were tested.

\section{Experimental}

Table 1 gives the actual chemical composition of tested steels. After casting, steel ingots were cut into slabs with a grinding wheel cutter. Then these slabs were partitioned into blocks with a Type DK77 numerical controlled wire-electrode cutting machine tool. These specimens were heat treated according to following procedures. First, they were heated at $1020^{\circ} \mathrm{C}$ for $0.5 \mathrm{~h}$, air cooling to room temperature, or heated at $1160^{\circ} \mathrm{C}$ for $24 \mathrm{~h}$, furnace cooling to room temperature. Second, they were austenized at $860-980^{\circ} \mathrm{C}$ for $0.5 \mathrm{~h}$, water quenching. Third, tempering was carried out at $150^{\circ} \mathrm{C}-600^{\circ} \mathrm{C}$ for $2 \mathrm{~h}$. Austenization is performed in Type SSJ-IIA high temperature chamber electric furnace and low temperature tempering is carried out in Type SX2-8-10 chamber electric furnace. 
Table 1 Chemical composition of investigated steels, mass \%

\begin{tabular}{ccccccccc}
\hline Steels & $\mathrm{C}$ & $\mathrm{Si}$ & $\mathrm{Mn}$ & $\mathrm{Cr}$ & $\mathrm{Mo}$ & $\mathrm{Al}$ & $\mathrm{Ni}$ & others \\
\hline LAWRS & 0.29 & 1.82 & 0.94 & 1.96 & 0.30 & 0.03 & - & - \\
LAWRS-Ni & 0.30 & 1.85 & 1.00 & 1.94 & 0.35 & 0.33 & 0.31 & - \\
LAWRS-V & 0.30 & 1.79 & 0.97 & 1.96 & 0.32 & 0.05 & - & V0.19 \\
LAWRS-C & 0.41 & 1.83 & 0.98 & 1.95 & 0.31 & 0.04 & - & - \\
\hline
\end{tabular}

Type Olympus GX51 optical metallography acquisition system and Hitachi Type S-4300 scanning electron microscope (SEM) were used to observe the microstructure. The EPMA-1610 (Electronic Probe Microscope Analysis) was also employed to test the elements distribution, whose specimen preparation was the same to that of SEM analysis. The etching solution of the experimental steels was composed of $4 \%$ nitric acid and $96 \%$ alcohol.

\section{Results and Discussion}

\subsection{Microstructure in homogenizing procedure}

The OM (optical microstructure) and EPMA images of steels after homogenizing were gave in Figure 1. The homogenizing procedure was conducted at $1160^{\circ} \mathrm{C}$ and kept for 24h. As shown in Figure 1 (a), microstructure of
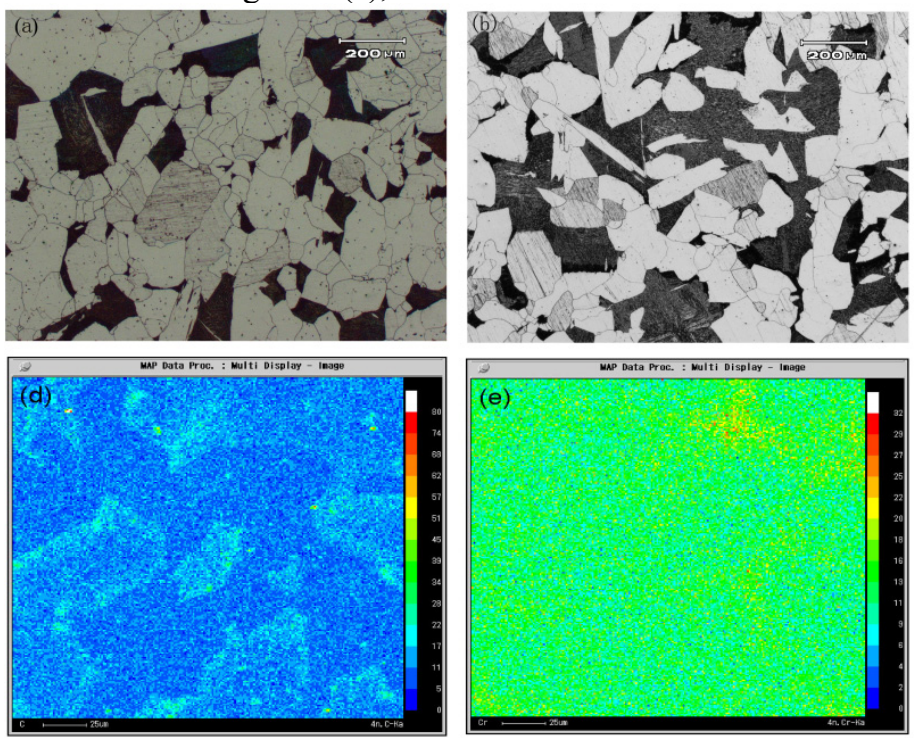

LAWRS samples was consisted with pearlite (the black region) and ferrite (the white and grey region). To be explicated, the white and grey region characterized two different orientations of ferrite. The average grain size of pearlite was about $100 \mu \mathrm{m}$. Figure 1 (b) showed microstructure of LAWRS-C steel, which contained 0.4 $\mathrm{wt} \%$ Carbon. Volume fraction of pearlite increased, and some of its grain size was up to $200 \mu \mathrm{m}$. That was to say, increasing carbon content leads to coarse grains and more sharp angle pearlite blocks.

Through EPMA images, it could be shown that Carbon and Chromium elements segregated in ferritepearlite boundaries and pearlite block, while vanadium exhibited no obvious segregation in this dimension. This indicated that during furnace cooling in homogenizing, Chromium/iron carbides composed, while few Vanadium atoms existed as carbides. This might be due to the outward movements of carbon in early formed ferrite during its growing process.
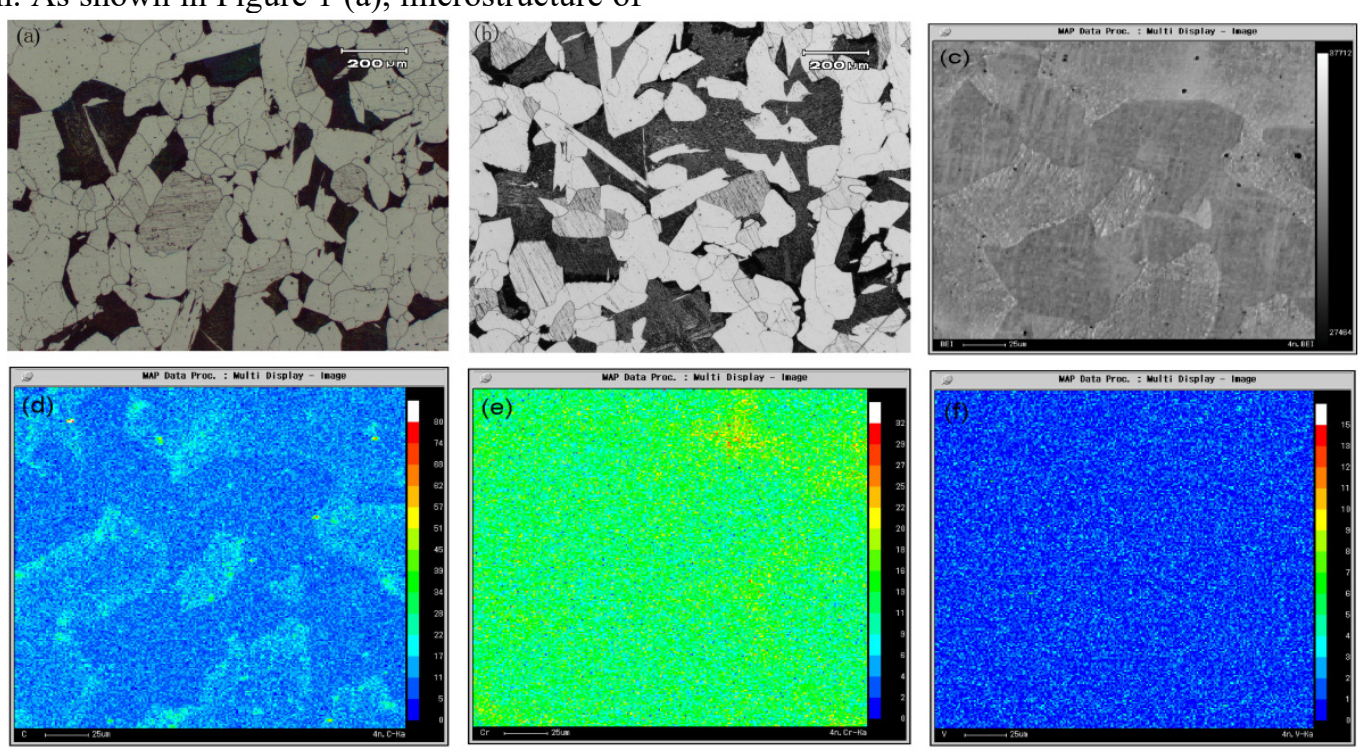

Figure 1. Images of OM and EPMA of steels after homogenizing at $1160^{\circ} \mathrm{C} \times 24 \mathrm{~h}$.(a) LAWRS, (b) LAWRS-C, (c)-(f) EPMA images of LAWRS-V, (d) Carbon distribution in EPMA, (e) Chromium distribution in EPMA, (f) Vanadium distribution in EPMA.

\subsection{Microstructure in quenching procedure}

It could be seen that, after homogenizing, particles contained iron/chromium carbides, whose precipitation nose temperature was around $650^{\circ} \mathrm{C}$. Thus, these particles would mostly be resolved into austenite matrix during austenizing. To testify this, the experimental steels were austenized at $940^{\circ} \mathrm{C}$ for $0.5 \mathrm{~h}$, then quenched to room temperature. The results were shown in Figure. It can be seen that, lots of particles still existed in the martersite. And most of them distributed along the boundaries, such as grain boundaries, martensite block boundaries, martensite lath boundaries. That could indicate that, the particles were mainly formed during furnace cooling in homogenizing procedure. And in the austenizing procedure, the temperature was not high enough for the particles to resolve. As mentioned above, the iron/Chromium carbides would resolve in austenizing. This would deduce that the particles might be Niobium and Mo carbides, which precipitate nose temperature were about $920{ }^{\circ} \mathrm{C}$ and $860{ }^{\circ} \mathrm{C}$ respectively. However to identify the composition of the particles, the EPMA and EDS should be conducted. Moreover, from the images, it also showed that the Carbon addition accelerated the growth of carbides. And the shape of carbides changed 
from small rod shape to shuttle shape. Is also seemed that the carbon addition would prompt the austenite growth, which lead to larger grain size, comparing with the LAWRS steel. On the other side, Ni addition only broadened the martensite lath width without dilating the austenite grains. And it hardly influenced the carbides formation. Vanadium addition seemed that the martensite lathes were cut into servaral discontinues sections. Reason for this has not cleared yet. It might related to the retardation of austenite transformation during heating in the austenizing procedure. Since Boron distributed
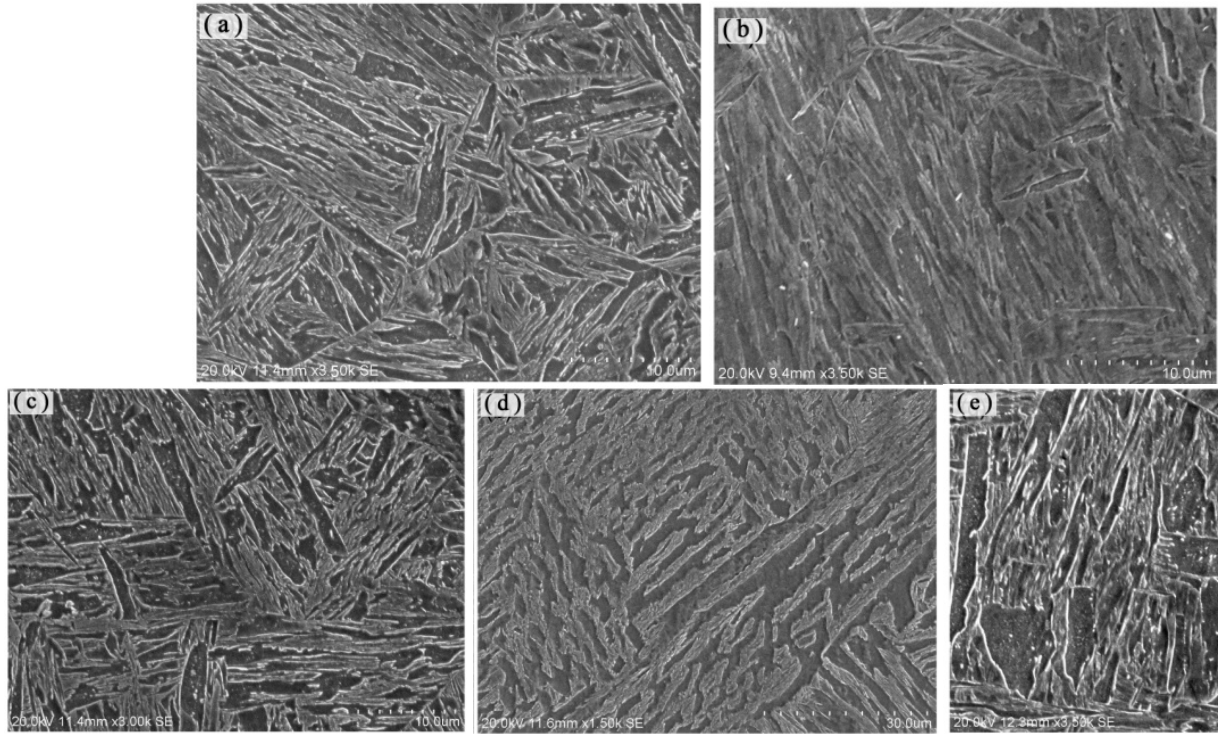

mainly along the boundaries, the Boron addition increased the content of carbides.

From the results, it could conducted that the carbides content was excessive for the carbides formation. And with the addition of Vanadium and Boron element, the quantity of carbides would distinctly raise, while with $\mathrm{Ni}$ and $\mathrm{C}$ addition, the solid solution strengthening would be significantly improved. But, the stablility of martensite would correspondingly decrease, which might lead to poor impact toughness.

Figure 2. OM images of experimental steels after quenching procedure of $940^{\circ} \mathrm{C}$ for $0.5 \mathrm{~h}$. (a) LAWRS steel, (b) LAWRS-C steel, (c) LAWRS-Ni steel, (d) LAWRS-V steel, (e) LAWRS-B steel.

To verify the carbides, EPMA of LAWRS steel after $1160^{\circ} \mathrm{C} \times 1 \mathrm{~h}$ homogenizing and $940^{\circ} \mathrm{C} \times 0.5 \mathrm{~h}$ austenizing followed by water quenching to room was conducted. The results, shown in Figure 3, indicated that Chromium element was homogeneously dispersed. Since the Chromium atom could substitute the iron atom in the
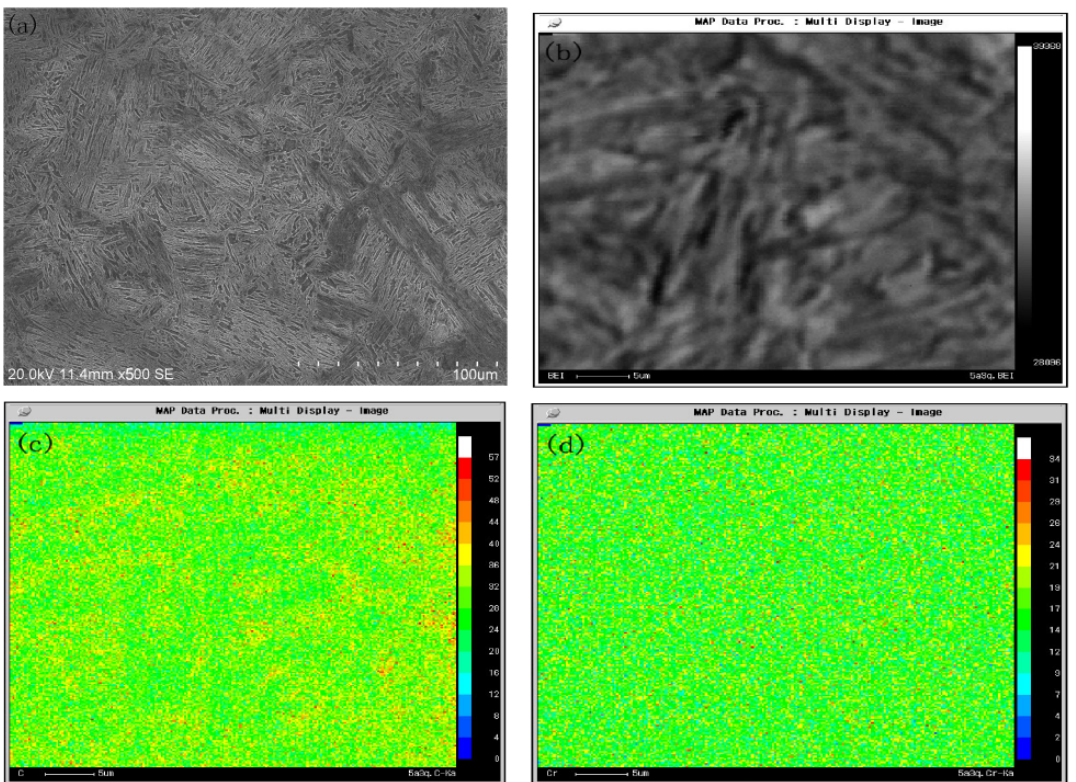

Figure 3. Images of EPMA of LAWRS steel after $1160^{\circ} \mathrm{C} \times 1 \mathrm{~h}$ homogenizing and austenizing at $940^{\circ} \mathrm{C}$ for $0.5 \mathrm{~h}$ and water quenching to room temperature. (a) microstructure by SEM; (b)-(d) images of EPMA, (c) Carbon distribution in EPMA; (d) Cr distribution in EPMA. 


\subsection{Microstructure in tempering procedure}

SEM images of LAWRS steel after quenching at $920^{\circ} \mathrm{C}$ and tempering at different temperatures were shown in Figure 4. During tempering, carbides existed after quenching barely changed. But the retained austenite would decomposed into ferrite and $\mathrm{Fe}_{3} \mathrm{C}$, and with the tempering temperature raising, from room temperature to $520{ }^{\circ} \mathrm{C}$, the $\mathrm{Fe}_{3} \mathrm{C}$ character would change, including shape, size and content. Therefore, the microstructure evolution of steels with Carbon, Ni, Boron and Vanadium
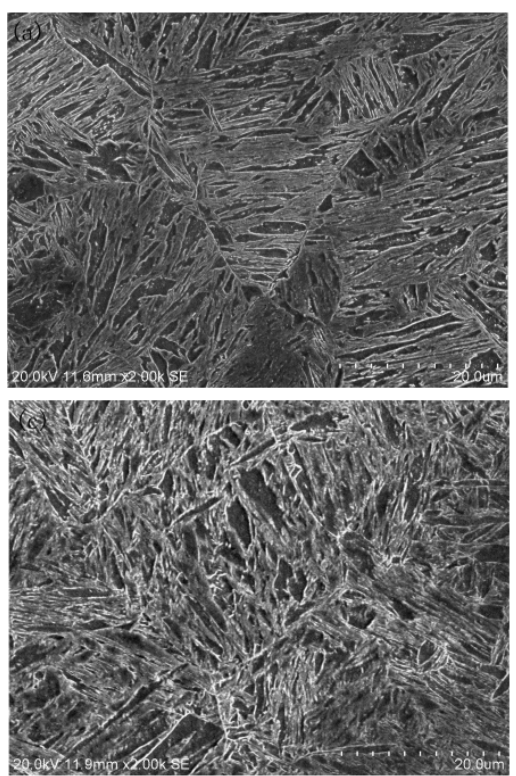

addition would be similar. So the LAWRS steel tempering at different temperatures was studied as the representive sample. It can be seen that the temperature mainly effect the martensite lath boundaries. With the temperature raising, the boundaries varied obviously. This might be correlated with the location of retained austenite. As mentioned in previous works, the retained austenite mainly formed along the martensite lath boundaries. Therefore, with the retained austenite decomposing, the lath boundary blurred, as shown in Figure 4 .
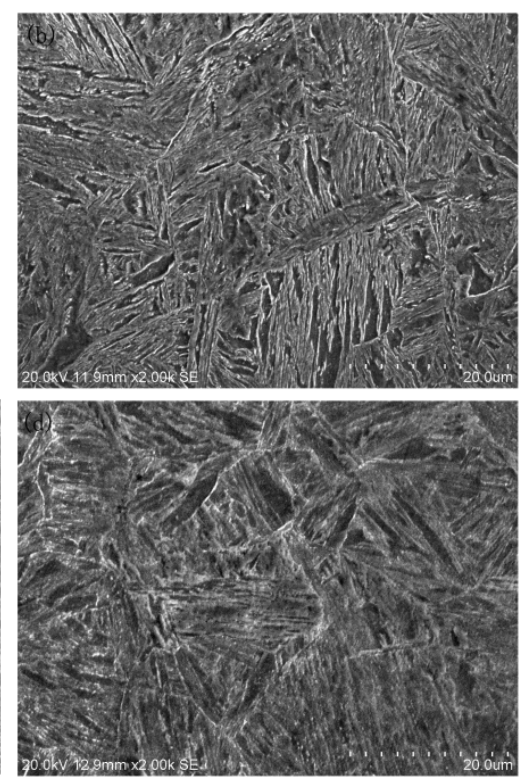

Figure 4. SEM images of LAWRS steel after quenching at $920^{\circ} \mathrm{C}$ and tempering at different temperatures. (a) tempering at room temperature, (b) tempering at $380^{\circ} \mathrm{C}$, (c) tempering at $460^{\circ} \mathrm{C}$, (d) tempering $520^{\circ} \mathrm{C}$.

\section{Conclusion}

The conclusion were as following: From the experiment, several conclusions could be brought out as following.

- During furnace cooling in homogenizing, Chromium/iron, Niobium, Vanadium and other hardly soluble carbides formed. But Chromium/iron carbides could resolve into austenite during quenching procedure, while the other carbides barely changed.

- Carbon addition grew the carbides into shuttle shapes and inflated the austenite grains. But Ni addition broadened the martensite lath width without dilating the austenite grains. And it hardly influenced the carbides formation. Vanadium addition seemed that the martensite lathes were cut into several discontinues sections.

- With the temperature rising, the boundaries got blurred, which might correlated with the decomposing of retained austenite.

\section{Acknowledgments}

This paper is supported by This work was financially supported by the National Science Foundation for Young Scientists of China (Grant No. 51601044, 5176504), Guangxi Natural Science Foundation (NO. 2015GXNSFBA139225, 2018JJA160266), the Opening Project of Guangxi Colleges and Universities Key Laboratory of robot \& welding: Re-search of microstructure and mechanical properties on CLAM steel after EBW and the Doctor's Research Initial Fund of Gulin University of Aerospace Technology: Researches on Rapid Die Design methods for Sheet metal, and Study on improving the microstructure stability of the heat resistant steel by modifying the precipitates.

\section{References}

1. V. Javaheri, The international journal for computation and mathematics in electrical and electronic engineering, 39 (2020) 158-165.

2. B. Białobrzeska, R. Dziurka, A. Żak, et al., Archives of Civil and Mechanical Engineering, 18 (2018) 413 -429 . 
3. x. DENG, Z.W. ANG, Y. HAN, et al., JOURNAL OF IRON AND STEEL RESEARCH, INTERNATIONAL, 21 (2014) 98-103.

4. V.G. Efremenko, V.I. Zurnadzhi, Y.G. Chabak, et al., Materials Science, 53 (2017)

5. Yuqing Weng, Caifu Yang, Chengjia Shang. Iron, 46 (2011)

6. H.Karbasian, A.E.Tekkaya, Journal of Materials Processing Technology 210 (2010) 2103-2118.

7. B. BIAŁOBRZESKA, W.D. ński, Archives of Metallurgy and Materials, 60 (2015) 1649-1656.

8. B. Białobrzeska, R. Dziurka, A. Żak, et al., Archives of Civil and Mechanical Engineering, 18 (2018) 413 $-429$. 